\title{
References
}

1. Bonner, Arnold. British cooperation: the history, principles, and organization of the British Cooperative Movement. 2nd ed. Manchester: Cooperative Union, 1970, p55.

2. Holyoake, George Jacob. The history of cooperation. London: T Fisher Unwin, 1906, p647.

3. Barnish, Edwin. The cooperative libraries of Lancashire, Yorkshire, and Durham. In: Transactions and proceedings of the second annual meeting of the Library Association. Manchester 1879. London: Whittingham, 1880, p61.

\section{Use of diaries in library and information research}

\author{
DEBORAH GOODALL \\ Centre for Research in Library and Information Management \\ University of Central Lancashire
}

\begin{abstract}
"Only good girls keep diaries. Bad girls don't have the time"* - one reason perhaps why the diary has never really developed as a research tool in library and information science!
\end{abstract}

This article explores the limited use, and limitations on use, of the diary within the context of LIS research. The author is currently working on a BLRDD funded project**, examining library support for franchised courses in higher education, which is utilizing the diary method to record library use by students. A brief literature review, searching for examples of successful diaries and models of good practice, was not as informative as had been expected, so this discussion aims to highlight some useful sources. The author welcomes correspondence and would be pleased to receive further examples of diary surveys.

It is surprising that diaries are barely mentioned in several LIS methodology books (eg Busha ${ }^{(1)}$, Salter ${ }^{(2)}$ ) and, apart from the Mass Observation ${ }^{(3)}$ work established in the 1930s, there is relatively little discussion of diaries as a popular research method even in the sociology field. One author notes that "while there are a good number of literary diaries .. there still remains remarkable little sociological usage. ${ }^{(4)}$ Ken Plummer ${ }^{(5)}$ usefully delineates between three types of diary, namely the requested, the log, and the diarydiary interview, but is less helpful regarding their actual use. On the whole it would seem that diaries are best avoided. As a documentary source of data they are described of as being part of the "paper jungle" by Mann ${ }^{(6)}$, writing from a sociological point of view, and Slater ${ }^{(7)}$, taking more of an LIS approach, warns that being, as they are, simply recorded self-observations, "they will have been subjected to some systematization and editing by their creators, at the conscious or unconscious level." Ensuring reliability is a serious issue and it is advised that "(those) who use such documents have to ask themselves whether the evidence therein is authentic, whether it is complete, how representative it is of the experiences described, whether it is distorted by the personal bias of the writer, and why it was written." (8)

In the LIS arena Davis ${ }^{(9)}$ gives a brief critical appraisal of the use of diaries in her 1971 article considering new approaches to studying library use. She comments "when fully and accurately maintained and analyzed, it provides the most specific data that can be found on user needs."(10) However there are doubts about the quality and quantity of data collected; ironically it is the busy respondent who is likely to be least accurate in recording details. Davis is one of the first of several writers to express concern that the analysis of the gathered data will be "difficult to accomplish."(11)

Library Support For Franchised Courses in Higher Education, funded by BLR\&DD June 1993-May 1995. Project head Prof Peter Brophy. For further information contact the Centre for Library \& Information Management, University of Central Lancashire, Preston PRI $2 H E$. 
Line comments fairly neutrally on the use of diaries by library researchers but notes that their use "is not without its problems." (12) Specifically he is concerned with the problems of obtaining a random sample: "it is certainly possible to draw a random sample and ask all those selected to cooperate, but those who can be induced to do so are likely to be a pretty small self-selected group. This group will become even smaller and less representative if the period over which the diaries are kept is long enough to be worthwhile, so that in the end one is left with a few individuals whose persistence is only one of their many non-typical features. Even if they are all honest and conscientious, the likely error is fairly substantial."(13) Line continues "if the nature of the inquiry allows it, it is much more satisfactory for a large number of individuals to keep diaries for a very short period (say four days). For some inquiries, however, the diary method may be the only way of obtaining data; and even at the worst a few nontypical individuals can yield information of some interest and value."(14)

Some studies have overcome problems of motivation by providing some token payment but these have not necessarily achieved the best response rates. Similarly there is conflicting evidence regarding the most appropriate time-span for diary-keeping. These points are explored in a comprehensive, and wellillustrated, discussion of diary use in LIS work given by Geoffrey Ford in his review of methods employed in determining the use of library stock. ${ }^{(15)}$ Ford suggests that the case for using diaries as a method of data collection rests on the assumption that this is a better way of obtaining facts than questionnaires and interviews but the examples he gives show that this is often not so. Researchers examining reading habits of, for example, scientists and technologists, found that it was difficult to get respondents to maintain interest for more than short periods and that the results did not justify further research. ${ }^{(16)}$ Similarly an Aslib diary study concluded that "the data collected were rich in variety, but have so far defied all attempts at analysis."(17)

Researchers working with students would seem to have more success. Again Ford gives useful examples including the 'instant diary' which was used at Lancaster University in 1971-73. ${ }^{(18)}$ A panel of 53 students were given forms to be completed on their next visit to the library. These forms comprised a structured questionnaire to be completed when the student arrived, stating the purpose of the visit, together with a diary to be completed during the visit. The data collected thus comprised a record of intentions and achievements.

In other more detailed studies students were asked to keep diaries of particular trips to the library, recording, for example (at the University of Kansas), starting and finishing times for each activity, the area of the library used, activities performed and satisfaction levels. Ford notes that "on a small scale the results are not significant but the method proved to be a viable one for recording these data. On a larger scale it could be used to gather information on the amount of use of various library services and their impact; the provision of books being one library service, clearly this method can be used to gain one measure of book use."(19)

A more ambitious longitudinal approach was used by Beheshti in 1989 to study the use of library books by undergraduate students in Canada.(20) Student volunteers used structured diaries to record the time they spent browsing/reading borrowed library books during a two month period. The results are interesting in spite of the rather technical presentation and showed that the average time spent reading/ browsing a book is about 50 minutes per user per day and that the major portion of use occurs during two days of the loan period.

Line $^{(21)}$ used structured diary forms, essentially checklists, which could be used to indicate action taken after a reference or book had been found in the library. Thus this was an attempt to measure the success of the diary in meeting potential demand and while generally a useful approach Line notes the difficulties in obtaining the cooperation of sufficient users to get representative results and ensuring that users are conscientious in completing the forms.

On the whole it would seem that the diary method is not as user-, or even researcher-friendly as would be expected. Although diaries allow users' actions and reactions to events to be recorded at the time of occurrence essentially people are not used to keeping a record of their activities. Without a predetermined structure for recording, the data are likely to be somewhat undigested and difficult to analyze. Considering overall the studies discovered during the literature review the response rates seem better where a more structured diary approach is used but this obviously limits the possible responses and insights. 
In the UK one of the most substantial diary based projects was the 'information needs of undergraduates' work which used a combination of observation, interview and diary techniques to investigate students' work habits, library use and the communications about work received from staff. This work was carried out by the Centre for Research on User Studies (CRUS) in the early 1980s and is reported in several $\operatorname{articles}^{(22)}$. Seventy-one students were asked to keep diaries for three specified weeks during an academic year, recording any work they had been set for their tutorials and what books etc. they had used to carry out the work besides the source of the information. A response rate of $94 \%$ was achieved and findings are descriptive and enlightening. Apparently the diaries were designed to be as simple and quick to complete as possible, while still giving detailed information, but in retrospect they look dated and longwinded. It is interesting to see that even diaries currently used by some market research companies look remarkably unsophisticated. ${ }^{(23)}$

Physical design and layout of diaries is clearly a problem. Early diaries, particularly those mentioned earlier by Ford, resembled little more than checklists and the main concern appeared to be with cramming as many questions into as small a space as possible with little thought for the respondent. Recent research by Crump ${ }^{(24)}$ at Leeds Metropolitan University has examined some of the issues surrounding diary design. The focus of Crump's work was the effectiveness of diaries as a method of determining how students spend their time. Two forms of diary, a time diary and a prompted diary, were piloted among a sample of 36 full- and part-time students to establish the most appropriate method of gathering information on how students spend their time on learning related activities. A $£ 5$ gift voucher was offered as an incentive/thank you.

Respondents were briefed and asked to complete both diaries over a seven day period with the time diary to be completed throughout the day and the prompted diary at the end of the day. The students were also asked to make a note of any problems or suggestions they had regarding the mechanics of completing the eiders, the codes, questions and format used and these were discussed during a debriefing meeting. Crump's report usefully concentrates on the views and opinions of the two types of diary. In summary Crump found that "on balance a mixture of the two diaries would appear to be the best compromise for the majority of respondents. The prompted diary appeared complicated and caused a number of respondents some concern when they only completed a small proportion of it."(25) Crump suggests that prompted diaries would have to be tailored to full-and part-time students as their behaviour is so different, whereas the same time diary could be used by both types of students with a small amount of adaptation to the codes. It was also suggested that if the diary were to be produced in booklet form the time sheet could be on the left hand page and space for prompted and free comment on the right.

Crump's research usefully informed that being carried out by the Centre for Research in Library and Information Management at the University of Central Lancashire. Here, as part of a larger project looking at library support for franchised courses in higher education, a diary method is being used to examine the actual experience of students on franchised courses. Approximately 120 students, both full- and part-time but mainly first year, studying on a range of courses at two universities and six colleges, are involved in filling-in diaries to record library use as they complete specific pieces of assessed work throughout the academic year. The specific aims of the diary work are to document the actual experience of students in relation to the provision and availability of library resources, provide a clear understanding of how students satisfy their information needs, and look at the strategies adopted - are franchised students disadvantaged compared to in-house colleagues?

Students taking part in the study have to complete three or four diaries and to attend a follow-up group discussion and will receive a $£ 25$ 'thank you' fee. But even with this inducement there were problems in recruiting a sufficient sample. Whilst few, if any, students have admitted that they would have taken part in the study without the fee there seems also to be a contradictory feeling that the fee implied that there was a lot of work involved in completing the diaries. Additionally the target sample was primarily first year students as, it is assumed, they have fewer pre-conceptions about academic library services. However, it is quite difficult to make meaningful contact with these students at the beginning of term. Initially there was a desire to keep the study separate from the Department in which the students were studying but insufficient response was received to personalized letters sent to students at their home addresses. Much more interest was generated following personal appearances at the end/beginning of lectures by the Research Fellow to promote the survey work. This approach is problematic in that it must 
have emphasized the implicit approval of the survey by the teaching staff and it also meant that the samples were self-selected. It was simply not possible in the timescale allowed for setting up this work to establish pools of volunteers at the different academic institutions from which matching groups of respondents could be compiled but efforts were made to recruit evenly sized groups on the different courses.

There were also problems in identifying suitable pieces of work, with a substantial library element, for which comparable groups of students could complete their diaries. The Research Fellow liaised with teaching staff to idertify suitable pieces of work and these members of staff will also be interviewed regarding learning methods being employed in franchised courses, with particular reference to the implied need for library use and resources. For some courses only two or three pieces of assessed work were set over the whole year. In others, due to the rapidly increased class size, there is a much greater reliance on case-study work and student-selected topics. This has an impact on the survey work in that it will not always be possible to compare like with like and yet this very situation has arisen because of the problems in providing a library service for large numbers of students studying the same topic.

Focusing on particular assignments overcomes a common weakness of diary work by clearly indicating what should be included in the diary. Practically, it allows a fairly intensive examination of the issues; quantitatively, it is possible to make realistic comparisons across groups of students; and qualitatively it enables the findings to be placed within the study context for each student.

Not surprisingly the design and production of the actual diaries was limited by the available facilities and finance, and especially by the fact that the diaries were to be used by different groups of students at different institutions. Nevertheless it was possible to incorporate a fair amount of 'good practice'. The diaries are quick to complete and can be carried around as respondents are asked to complete their diaries as they do the piece of work. Each five page A4 booklet contains a brief introduction to the study, a student profile asking for basic information about the respondent, three copies of the "diary of activities' page plus some basic guidelines for completing the diary and an example of a completed diary page. As well as collecting chronological data on the time and place

of work the main interest of the diary forms is in finding out about materials used and (any, not just academic) library services/facilities used for the assignment. The respondent is asked to tick coded boxes to indicate what has been used and is also encouraged to give free comments in the second half of the page by referring to the relevant line number. Each diary page is self-contained and respondents complete as many or as few lines as necessary to record their activities. All students involved in the survey attended a briefing meeting when the first diaries were distributed. Subsequent diaries are handed out as required, sometimes by teaching staff, sometimes by the Research Fellow, to ensure that the momentum of the study is maintained.

The follow-up meetings, which will take place in the summer when all of the diaries have been returned and analyzed, will serve a number of purposes, not least in determining the typicality of the diary record. By using the diaries as an aide-memoire the students will be encouraged to reconstruct their way of tackling assignments and to describe the impact of any problems encountered and the strategies adopted to complete the work. The information gathered from the students themselves will be combined with that obtained by interviewing teaching staff (about their knowledge/perceptions/expectations of library use by their students) and library staff (regarding resources and information skills work for the courses in question) to give an overall picture of how students doing academic work use libraries. The information recorded in the diaries provides both an end-product, that is a record of actions taken, and a starting point for considering students' information strategies. Thus it will possible to compare in a dynamic way the experience of in-house and franchised students studying the same course at different locations.

\section{References}

1. Busha, C. H. \& Harter, S. P. Research methods in librarianship. New York: Academic Press, 1980 .

2. Slater, M. (ed.) Research methods in library and information studies. London: LAPL, 1990. 
3. McNeill, P. (ed.) Research methods. London: Routledge, 1990, pp. 2-4.

4. Plummer, K. Documents of life. London: Unwin 1983, p. 18.

5. Plummer, K. Documents of life. London: Unwin 1983, pp. 17-21.

6. Mann, P. H. Methods of sociological enquiry. Oxford: Blackwell, 1968, p. 81.

7. Slater, M. (ed.) Research methods in library and information studies. London: LAPL, 1990, p. 123.

8. McNeill, P. (ed.) Research methods. London: Routledge, 1990, p. 109.

9. Davis, D. L. New approaches to studying library use. Drexel Library Quarterly 7 (1) January 1971, pp. 4-12.

10. Davis, D. L. New approaches to studying library use. Drexel Library Quarterly 7 (1) January 1971, p. 8.

11. ibid.

12. Line, M. B. Library surveys. London: Bingley, 1982, pp. 50-51.

13. ibid.

14. ibid.

15. Ford, G. Review of methods employed in determining the use of library stock (BNBRF Report 43). London: The British Library, 1990.

16. p. 9.

17. p. 9.

18. p. 9 .

19. pp. 10-11.

20. Beheshti, J. A longitudinal study of the use of library books by undergraduate students. Information Processing \& Management 25 (6), 1989, 737-744.

21. Ford p. 10 .

22. See, for example, the articles by Cherry Harrop and Brian Clifford in CRUS News 10 (March 1981), 11 (July 1981), 12 (November 1981) and 14 (July 1982).

23. For example, the Marvel Powdered Milk diary forms distributed by Millward Brown during June 1993.

24. The effectiveness of diaries as a method of determining how students spend their time. Leeds Metropolitan University, April 1993 (internal document kindly made available by Ms. K. Crump).

25. The effectiveness of diaries as a method of determining how students spend their time. Leeds Metropolitan University, April 1993, p. 9. 